\title{
Compatibility of the Sizing System in Wearable Products
}

\author{
Youngsuk LEE \\ Department of Clothing Science, University of Chonnam, Gwangju, Korea \\ ysl@.chonnam.ac.kr
}

\begin{abstract}
Anthropometric data are collected and used by all types of organizations for many types of applications. These including universities, hospitals, health statistics departments, militaries, apparel companies, furniture manufacturers, automobile manufacturers, safety equipment companies, aerospace companies, and many other industries and organizations. This paper was performed to summarizes some of the objective data to get the comparison of the sizing systems and body shape distributions between countries and to develop few solutions towards an $<$ Online Size Information Tool $>$. I introduce the information tools I am developing for the clothing market globalization using the following data: Anthropometric measurement data source, Standards in clothing, Sizing systems of KS, AFNOR, ISO, JIS, ASTM, AUS,. Distribution of the key dimensions, Distribution of the 2ndary dimensions and the comparing size samples from different countries
\end{abstract}

Keywords: Compatibility, Sizing System, Clothes, Body shape, Key Dimension, Standards

\section{Introduction}

In the new trend of globalization, one may think that all humans may one day finally not be very different from each other, eating other country dishes, dressing more or less all in the same manner, behaving along a more unified way of thinking. This is already true to a certain extent, and the trend with several pauses and reactional short periods, will probably continue. But, interestingly one of the most important element of globalization (beside profit), the ever wide spreading of information all over the world, seems to contain in itself the necessity of taking more and more in account the characteristic of individuals.

Indeed, with the technological information age which means also that every producer and market researcher looks more and more towards any information he can get about his customers (behavior, likings, cultural and physical features), to try to maximize his market. He may try to do without, but then may risk much, for others will probably not do so.

Another aspect of the dissemination of information and knowledge is also that consumers all over the world become at the same time more educated and will no doubt be more and more choosy. The average individual will probably not be too dissatisfied to have more or less an average product, as long as it fits well its desire and also his physical features. In one word, products will have to suit much more individuals.

In the field of clothing as in many others, advertisement will have to be paired increasingly with quality and suitably and rely somewhat less on consumer psychology. Individuals, even those who follow fashion trends, will give their preference to those producers who can produce garments which suit most their physical features.

Here comes then the importance of good physical features statistics, by countries, ages, sexes, and in multiracial societies, races or interracial types. Indeed such statistics allow to define some average virtual individual shape for each classes, recognize the growing importance of some of them, and changes occuring with the passing of time. Truly, these changes, though sometimes manifest, may even, in some cases, seem to not be recognized or reflected by such and such industry or maker until some statistical news are made public or profit has declined. To give a rather simple example, it is not at present, always that easy in case of some brands, to find in Korea shoes big enough for men for men more than $1,80 \mathrm{~m}$ high, though not so few Korean young men are now taller than this. Anthropometry data collections are becoming thus more and more of a necessity to the whole manufacturing community .

Here now, in view of the importance of e-shopping all over the world, and of the ever increasing worldwide travel and trade, online information tools seem to be increasingly necessary. In the context of these kinds of social and technical environmental changes, detailed on-line information tools about size and design data should be put at the disposal of both consumers and producers to help them choose the right garments and design the most suitable ones.

For this purpose, this paper strives to construct databases with these concepts for size compatibility and market share information between countries 


\section{Methods}

For the garment sizing system, we analyzed 50 items related to garment construction and body shape changes. This study used and analyzed the data of the Anthropometric measurements, standards in clothes, sizing systems of KS, AFNOR, ISO, JIS, ASTM, distribution of the key dimensions, distribution of the 2ndary dimensions and comparing size samples from differentent countries to construct the information tools for the globalization of the clothing market

The most important features of the analysis for the sizing system were:

1) grouping of samples by age classes, classes being defined themselves by a community of body shape characteristics. For these, we analyzed our data using factor and canonical analysis.

2) body shape grouping. For body shape grouping, we adopted the Chest-Waist Drop value for men, Bust-hip Drop value for women, in order to distinguish the body type, thus using methods used by ISO and many countries.

3) size pitch. For men, we choosed a $2 \mathrm{~cm}$ pitch in case of chest and waist, and for women $3 \mathrm{~cm}$ pitch for the bust, and a $2 \mathrm{~cm}$ pitch for the hips.

4) key dimensions. Body shape(drop value), height, proportion.

One of the aim of the above work and analyses has been, in order to facilitate the production work of the industry, to try to minimize the number of sizes to be defined whiling maximizing their cover rates.

\section{Results}

In this study we looked first at the size codes approximate correspondences between each system but looked also into more detailed information entailed in this codes, making conspicuous in an after-method body shape differences between countries (e.g. for such or height size, in some countries corresponding width come more or less important ,etc.) Such more detailed tables allow better comparison and can facilitate the determination of really needed sizes requirements in case of exportation or importation.

The following give an idea of some of the tables and graphs of correspondence made (Fig. 1. 2,3,4,5,6,7,8 ).

Defined sizes for the korean population were finally: For men, 5types: A (drop 14-18), Y(drop 18-22), YY(drop22-28), B(drop10-14), BB(drop6-10) with a total covering rate of $80 \%$ ( Table $1,2,3$ ),

For women, 3types: H(drop-4-6), N(drop4-12), A(drop 12-18), the first and third type being each subdivided in two(young, aged). Total covering rate being $85 \%$.

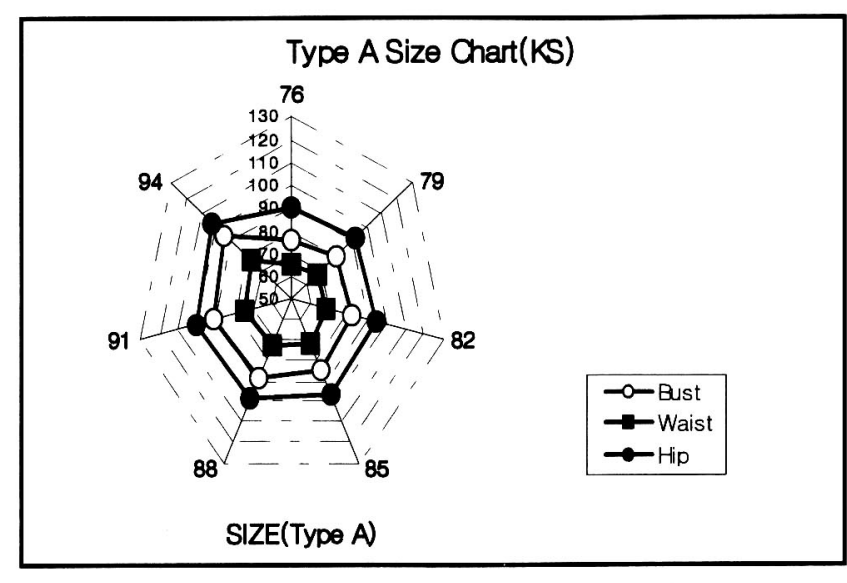

Figure 1. Body shape in type $A$ of KS

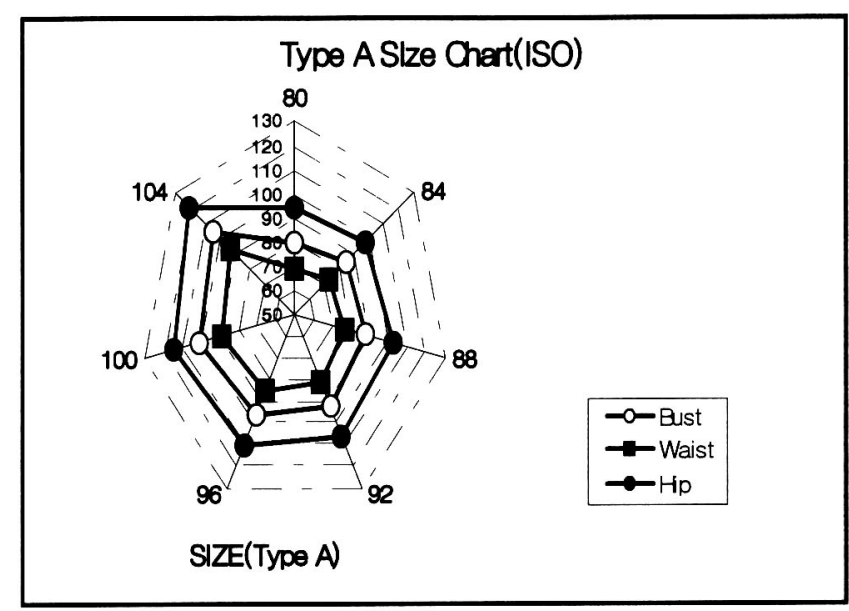

Figure 2. Body shape in type A of ISO

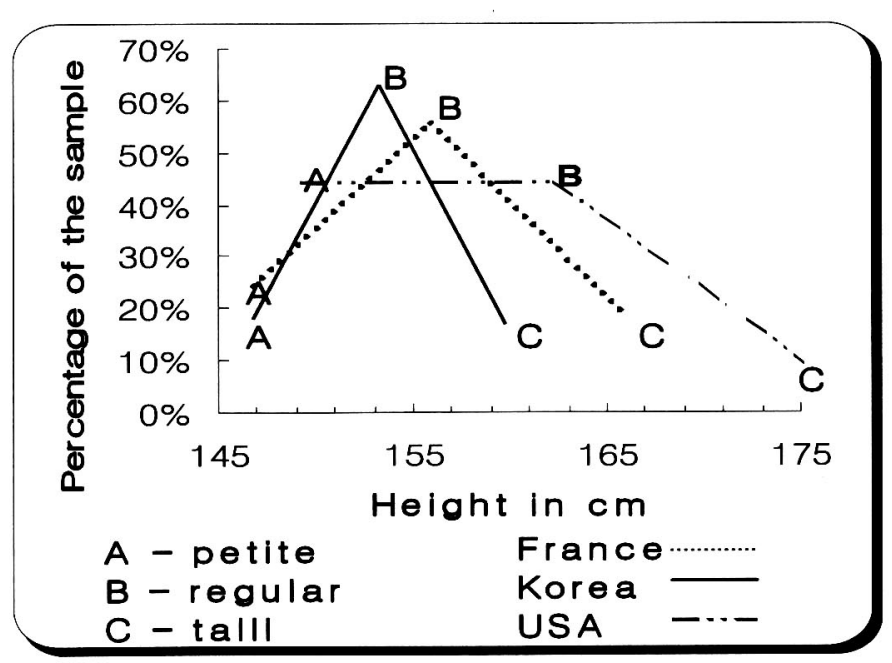

Figure 3. Height distribution 


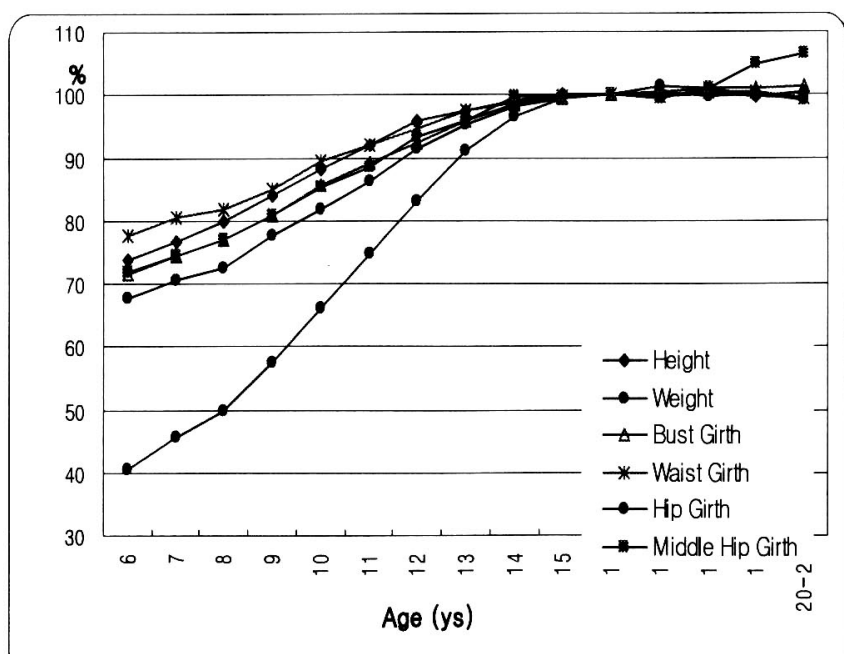

Figure 4. Size change by age

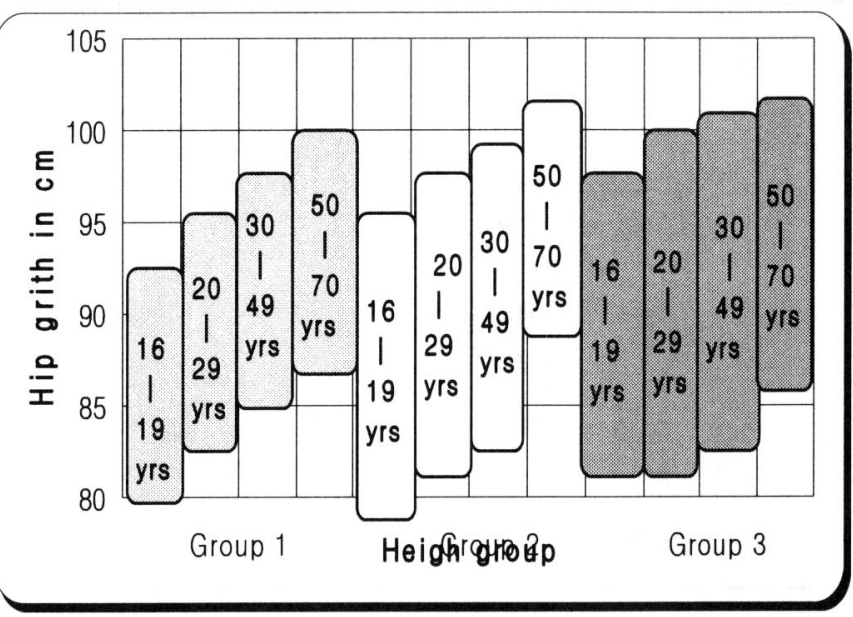

Figure 5. Hip girth distribution

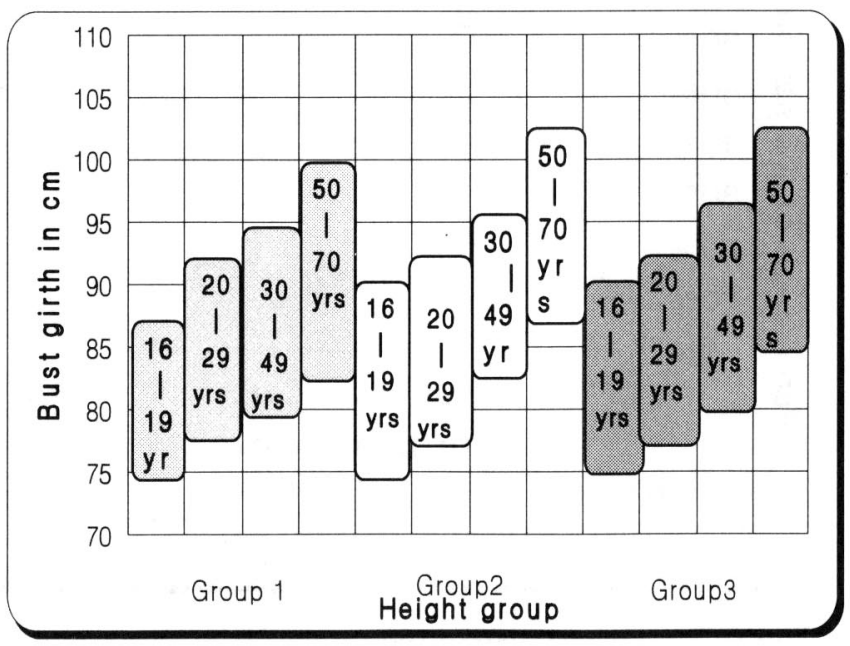

Figure 6. Bust girth distribution at each height

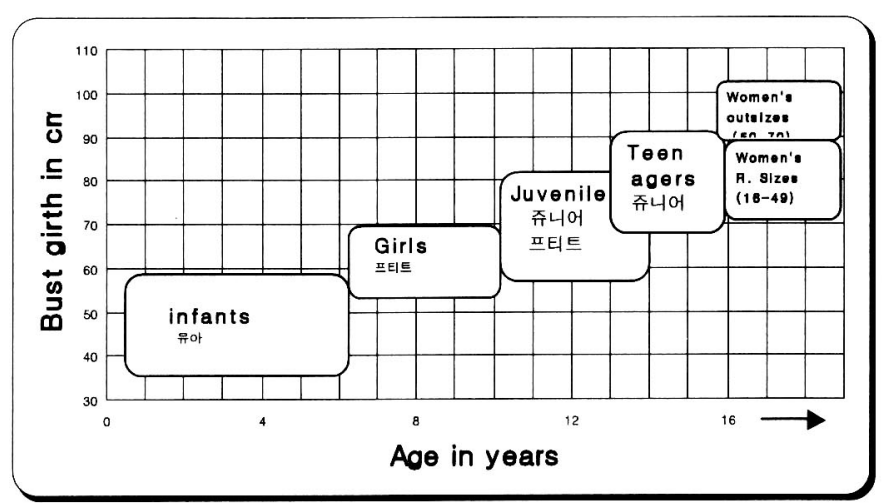

Figure 7. Bust girth range at each age group

Table 1. Comparison drop values at each body type

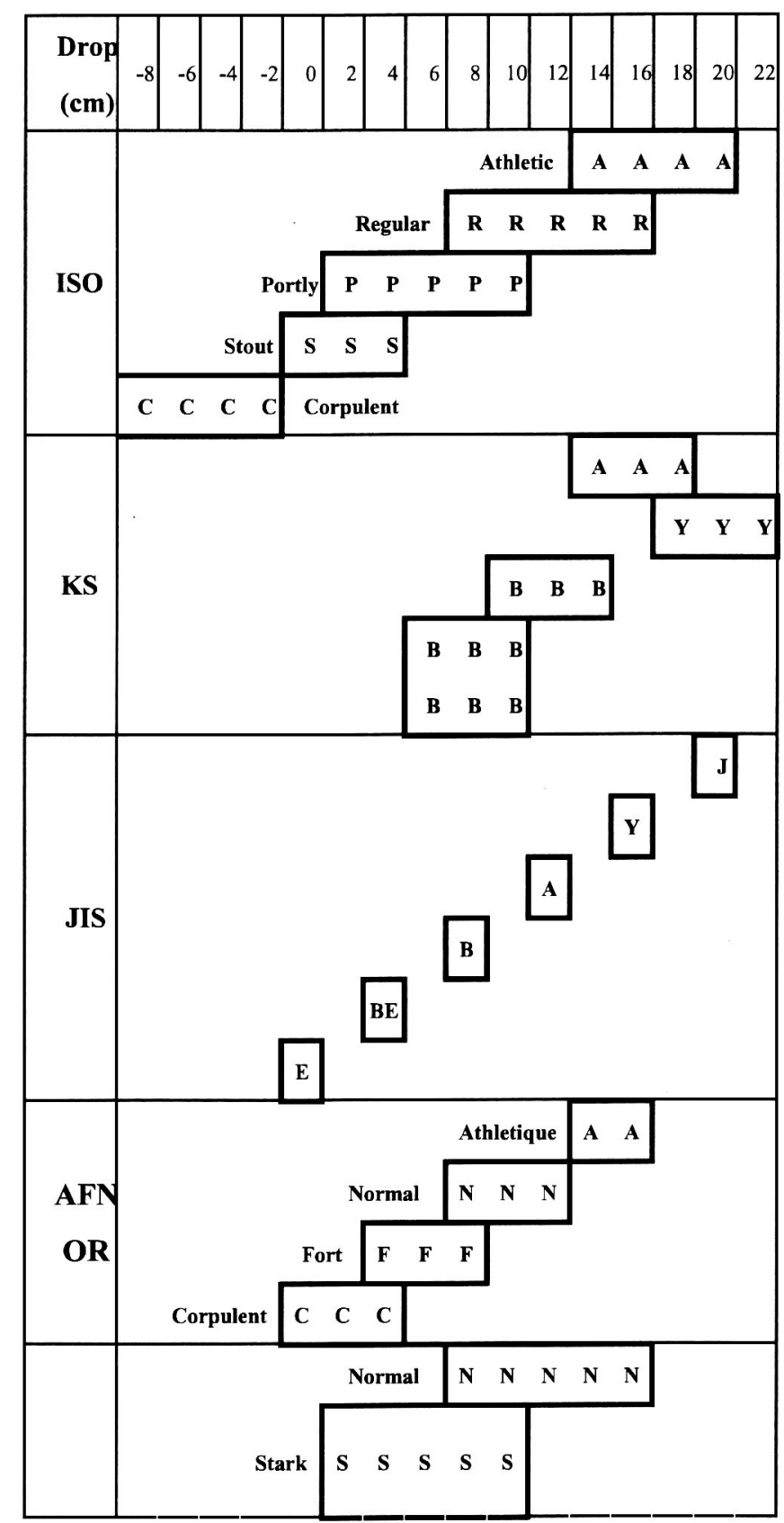


Table 2. Body types in Korean man

\begin{tabular}{|c|c|c|c|}
\hline & Petite & Regular & Tall \\
\hline & $155 \sim 165 \mathrm{~cm}$ & $165 \sim 175 \mathrm{~cm}$ & $175 \sim 185 \mathrm{~cm}$ \\
\hline $\begin{array}{c}\text { YY type } \\
\text { (Drop 22 28) }\end{array}$ & Drop $22 \mathrm{~cm}$ & Drop $24 \mathrm{~cm}$ & Drop $28 \mathrm{~cm}$ \\
\hline $\begin{array}{c}\text { Y type } \\
(\text { Drop } 18 \sim 22)\end{array}$ & Drop $18 \mathrm{~cm}$ & Drop $20 \mathrm{~cm}$ & Drop $22 \mathrm{~cm}$ \\
\hline $\begin{array}{c}\text { A type } \\
\text { (Drop } 14 \sim 18)\end{array}$ & Drop $14 \mathrm{~cm}$ & Drop $16 \mathrm{~cm}$ & Drop $18 \mathrm{~cm}$ \\
\hline $\begin{array}{c}\text { B type } \\
\text { (Drop } 10 \sim 14)\end{array}$ & Drop $10 \mathrm{~cm}$ & Drop $12 \mathrm{~cm}$ & Drop $14 \mathrm{~cm}$ \\
\hline $\begin{array}{c}\text { BB type } \\
\text { (Drop 6 10) }\end{array}$ & Drop $6 \mathrm{~cm}$ & Drop $8 \mathrm{~cm}$ & Drop $10 \mathrm{~cm}$ \\
\hline
\end{tabular}

Female(Bust girth-Hip girth)distribution, Total

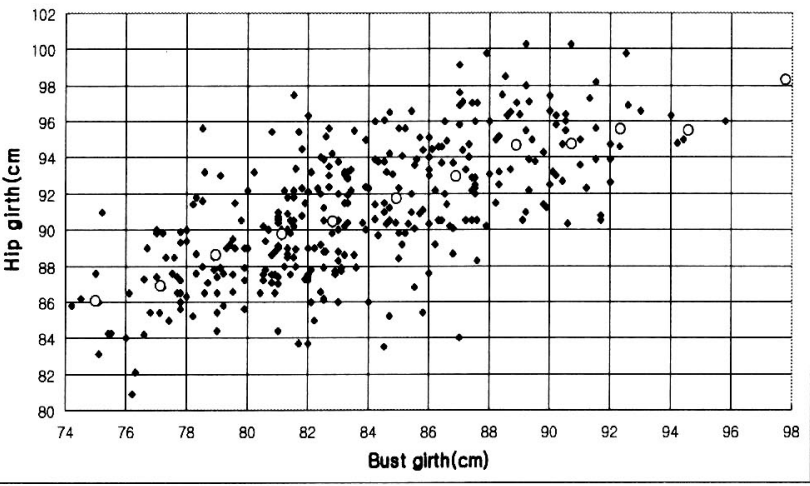

Figure 8. Bust girth distribution at each height

Table 3. Cover rate

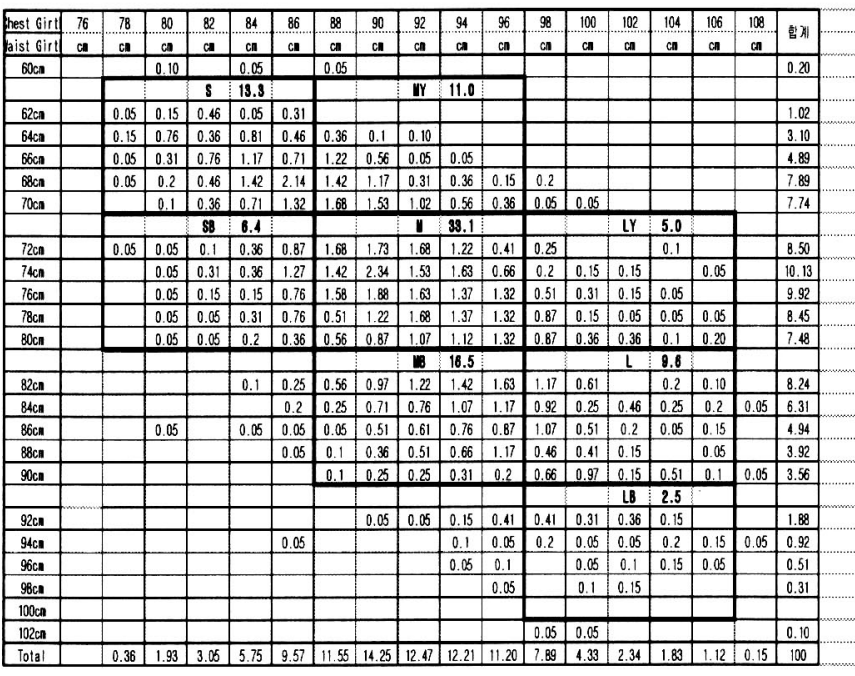

\section{Conclusion}

In Korea and Japan much research has been conducted about body shapes (flat, 3D) and comfort feeling, including physiological response, using already existing databases and constructing new ones. In particular, comfort but also design emphasizing or enhancing the beauty or grace of individuals are important elements being taken in account while trying to respect as much as possible the existing silhouettes and proportions characteristics of one's proper nation. Thus, from a wider viewpoint embracing different statistics from different countries, differences between western and oriental body frames must be well meditated, matter which has been here and there the focus of several punctual studies but not of large-scale systematic ones.

In this new era of globalization where East and West are becoming ever and ever closer the construction of important databases presenting and comparing these differences appear to be more and more of a necessity.

We must acknowledge that the making up for the customer and designer of information tools about sizes depends much on the volume and accuracy of the data made available by each country which in turn is usually connected with its level of development.

It has been suggested that online tools could be extended to cover non-anthropometric data such as social preferences about colors, shapes, wearing behavior for such -and -articles. As far as social preference trends(natural trends or induced trend through traditional life pattern) are concerned, online tools involving choices on a computer screen could be of course be made but they would be of a different nature : Instead of statistical data shown on charts or tables with an additional tool, social trend culture behavior report would most probably be text with picture or document to be traditionally obtained in a linear manner.

\section{References}

[1] Korea National Anthropometry Survey, Report of Korea National Institute of TQ, 1997.

[2] Y.S. Lee, Somototype in Koreans, 1998.

[3] Morpological study in Korean for the clothe Sizing System, Report of National Institute of Technology and Quality, 1999.

[4] Y.S. Lee and K.H. Lee, Comparison on Sizing Systems of Adults Outwears(ISO, KS, JIS, AFNOR, DIN, ASTM, UNI), 1999.

[5]Y.S. Lee, The Measure of Man; Human Body Dimension Data in Design, 1999.

[6]Y.S. Lee, The Measure of Woman; Human Body Dimension Data in Design, 1999.

[7]Y.S. Lee, The Measure of Youths; Human Body Dimension Data in Design, 1999.

[8]Y.S. Lee, The Measure of Infants; Human Body Dimension Data in Design, 1999. 